\title{
The Effect of Combining Fish Oil and Vitamin C on Airway Inflammation and Hyperpnea-Induced Bronchoconstriction in Asthma
}

\section{Timothy D Mickleborough ${ }^{1 *}$ and Martin R Lindley ${ }^{2}$}

${ }^{1}$ School of Public Health, Human Performance and Exercise Biochemistry Laboratory, Department of Kinesiology, Indiana University, Bloomington, IN, USA ${ }^{2}$ Human Cellular and Molecular Biology Research Laboratory, Inflammation, Exercise and Metabolism Research Group, School of Sport Exercise and Health Sciences, Loughborough University, UK

\begin{abstract}
Purpose: To compare the effects of two mono-therapies (fish oil and vitamin C) alone and in combination, on airway inflammation and the bronchoconstrictor response to eucapnic voluntary hyperpnea (EVH) in asthmatics.

Methods: Sixteen asthmatic subjects with hyperpnea-induced bronchoconstriction (HIB) entered the study on their usual diet (pre-treatment, $n=16)$ and then randomly assigned to receive either active vitamin $C$ tablets $(1.5$ $\mathrm{g}$ ) and placebo fish oil capsules $(\mathrm{n}=8)$ or active fish oil capsules $(3.2 \mathrm{~g} \mathrm{EPA} / 2.0 \mathrm{~g} \mathrm{DHA})$ and placebo vitamin $\mathrm{C}$ tablets $(n=8)$ taken for 3 weeks. Thereafter, all subjects (combination treatment; $n=16$ ) underwent a further 3 -week treatment period consisting of active vitamin C tablets and active fish oil capsules taken daily (NT01057615).

Results: HIB was significantly inhibited $(p<0.017)$ by fish oil, vitamin $C$ and combination treatment compared to pre-treatment (usual diet); percent fall in post-EVH forced expiratory volume in 1-sec was $18.8+5.7 \%, 9.7+$ $5.4 \%, 10.5 \pm 10.2 \%$ and $10.7 \pm 9.3 \%$ on the usual diet, fish oil, vitamin $C$ and combination treatment respectively. All three treatments, compared to the usual diet, were associated with a significant reduction $(p<0.017)$ in the fraction of exhaled nitric oxide and bronchodilator use, and improvement in asthma symptom scores and exhaled breath condensate $\mathrm{pH}$. There was no significant difference between treatment groups for any dependent variables.
\end{abstract}

Conclusion: While fish oil and vitamin $\mathrm{C}$ supplementation are both effective in attenuating airway inflammation and $\mathrm{HIB}$, combining these two nutrients does not confer a greater anti-inflammatory effect or suppression of HIB than either intervention alone.

Keywords: Omega-3 fatty acids; Ascorbic acid; Diet; Lungs; Exercise

\section{Introduction}

Approximately 25 million Americans have asthma, a chronic inflammatory disease resulting in airway inflammation, hyperresponsiveness, and narrowing [1]. One complication of this disease that can affect up to $90 \%$ of asthmatics is exercise-induced bronchoconstriction (EIB) [2]. The presence of EIB may indicate that an individual's asthma is not being adequately managed, and therefore it is of clinical importance to evaluate the effectiveness of asthma therapies [3].

Traditional pharmacologic approaches to managing asthma do not always provide adequate protection against EIB [4], which may be due to patients' variable responses to medications or side effects of the drugs. Thus, patients may seek out alternatives to asthma medications. Since it has been suggested that the prevalence of asthma may be related to dietary factors, numerous nutritional strategies have been examined that may impact the severity of asthma and EIB, such as a high ratio of omega-6: omega-3 polyunsaturated fatty acids (PUFAs) or a low antioxidant intake $[5,6]$.

Marine oil supplementation appears to be a promising approach to managing EIB $[7,8]$ and hyperpnea-induced bronchoconstriction (HIB) $[9,10]$. Fish oil is composed of the omega-3 PUFAs eicosapentaenoic acid (EPA) and docosahexaenoic acid (DHA), which can cause dual inhibition of cyclooxygenase-2 and 5-lipoxygenase (5-LO) pathways for metabolism of arachidonic acid (AA), an omega-6 PUFA. This would result in less biologically active pro-inflammatory mediators than the analogous arachidonic acid pro-inflammatory mediators [11] and a subsequent attenuation of airway inflammation and EIB in asthmatic individuals [12]. In addition, a new class of mediator families derived from fish oil, the EPA-and DHA-derived resolvins (RvE1 and RvD1), and the DHA-derived protectin (PD1) [13] and maresins [14], which act locally, and possess potent anti-inflammatory novel bioactions, may also play an important role in mitigating airway inflammation.

Various nutritional interventions have been shown to be effective in mitigating EIB. Fish oil supplementation has been shown to effectively reduce EIB in elite athletes without concurrent asthma [8], as well as in adults with asthma [7]. It has also been determined that fish oil and the leukotriene receptor antagonist montelukast each prevent HIB to a similar extent [10]. Similarly, vitamin $\mathrm{C}$ supplementation has been evaluated as a nutritional approach to managing asthma since it has been shown that adults with asthma have lower levels of plasma ascorbic acid (vitamin C) compared to healthy, non-asthmatic adults [6]. Supplementation with an antioxidant, such as vitamin C, may be beneficial for asthmatics because they have enhanced production of reactive oxidant species (ROS), which can damage the airway epithelium and cause airway inflammation [15]. A meta-analysis investigating vitamin $\mathrm{C}$ as a treatment for asthma determined that vitamin $\mathrm{C}$ has demonstrated only limited effectiveness [16]; however, this may be due to the incongruent protocols for supplementation and

*Corresponding author: Timothy D. Mickleborough, FACSM, School of Public Health, Department of Kinesiology, 1025 E. 7th St. SPH 112, Bloomington, IN 47404, USA, Tel: 8128550753; Fax: 8128553193; E-mail: tmickleb@indiana.edu

Received June 04, 2014; Accepted July 16 2014; Published July 23, 2014

Citation: Mickleborough TD, Lindley MR (2014) The Effect of Combining Fish Oil and Vitamin $\mathrm{C}$ on Airway Inflammation and Hyperpnea-Induced Bronchoconstriction in Asthma. J Allergy Ther 5: 184. doi:10.4172/2155-6121.1000184

Copyright: () 2014 Mickleborough TD, et al. This is an open-access article distributed under the terms of the Creative Commons Attribution License, which permits unrestricted use, distribution, and reproduction in any medium, provided the original author and source are credited. 
the different asthma bronchoprovocation tests used between studies. However, a more recent meta-analysis examining the effectiveness of vitamin $\mathrm{C}$ on EIB concluded that given the low cost this antioxidant, and positive findings of an attenuation of EIB following supplementation, patients with EIB should be encouraged to supplement their daily diet with vitamin C [17]. In support of the findings from this recent meta-analysis [17] we have previously shown [18] that a two-week, $1500 \mathrm{mg} /$ day regimen of pharmaceutical grade vitamin C, significantly reduced exercise-induced airway narrowing and airway inflammation in asthmatic adults with EIB.

Given that asthma is known to be a multi-faceted disease, it is possible that a nutritional approach incorporating multiple nutrients ("polypill" approach) will be more effective than any one nutritional supplement alone in attenuating EIB. In other words, simultaneously targeting various inflammatory pathways with multiple nutrients may result in a more pronounced reduction in EIB than using a single nutrient approach.

Therefore the purpose of this study was to determine whether the combination of fish oil and vitamin C supplementation offers increased protection against airway inflammation and hyperpnea-induced bronchoconstriction (HIB) compared to each intervention alone. It was hypothesized that fish oil and vitamin $\mathrm{C}$ supplementation taken in isolation will be effective in the diminution of airway inflammation and HIB in asthma, and that the two treatments combined will confer even greater protection.

\section{Methods}

\section{Subjects}

Thirty seven subjects were recruited to this study from a university and community setting, and seventeen were excluded for either not meeting the inclusion criteria $(\mathrm{n}=9)$ or declined to participate further $(\mathrm{n}=8)$. While twenty subjects entered the study trial, only data from sixteen subjects ( 9 male, 7 female; aged $23.4 \pm 1.1$ yr., height $1.72 \pm$ $0.47 \mathrm{~m}, 78.4 \pm 21.4 \mathrm{~kg}$ ), with both asthma and hyperpnea-induced bronchoconstriction (HIB), were used in the data analysis (Figure 1).

All subjects had physician diagnosed mild-to-moderate persistent asthma with a resting forced expiratory volume in one second (FEV1) greater than $60 \%$ of predicted, and greater than a $10 \%$ decrease in the FEV1 following dry gas hyperpnea, which is a surrogate for an exercise challenge test used to diagnose EIB [19]. An advantage of using EVH over exercise as the bronchial provocation challenge is that a higher ventilation rate can be achieved during the EVH test, without the need to exercise at a high level, and allows for greater control of ventilation and inspired air conditions [20].

A control group of healthy, non-asthmatic subjects was not

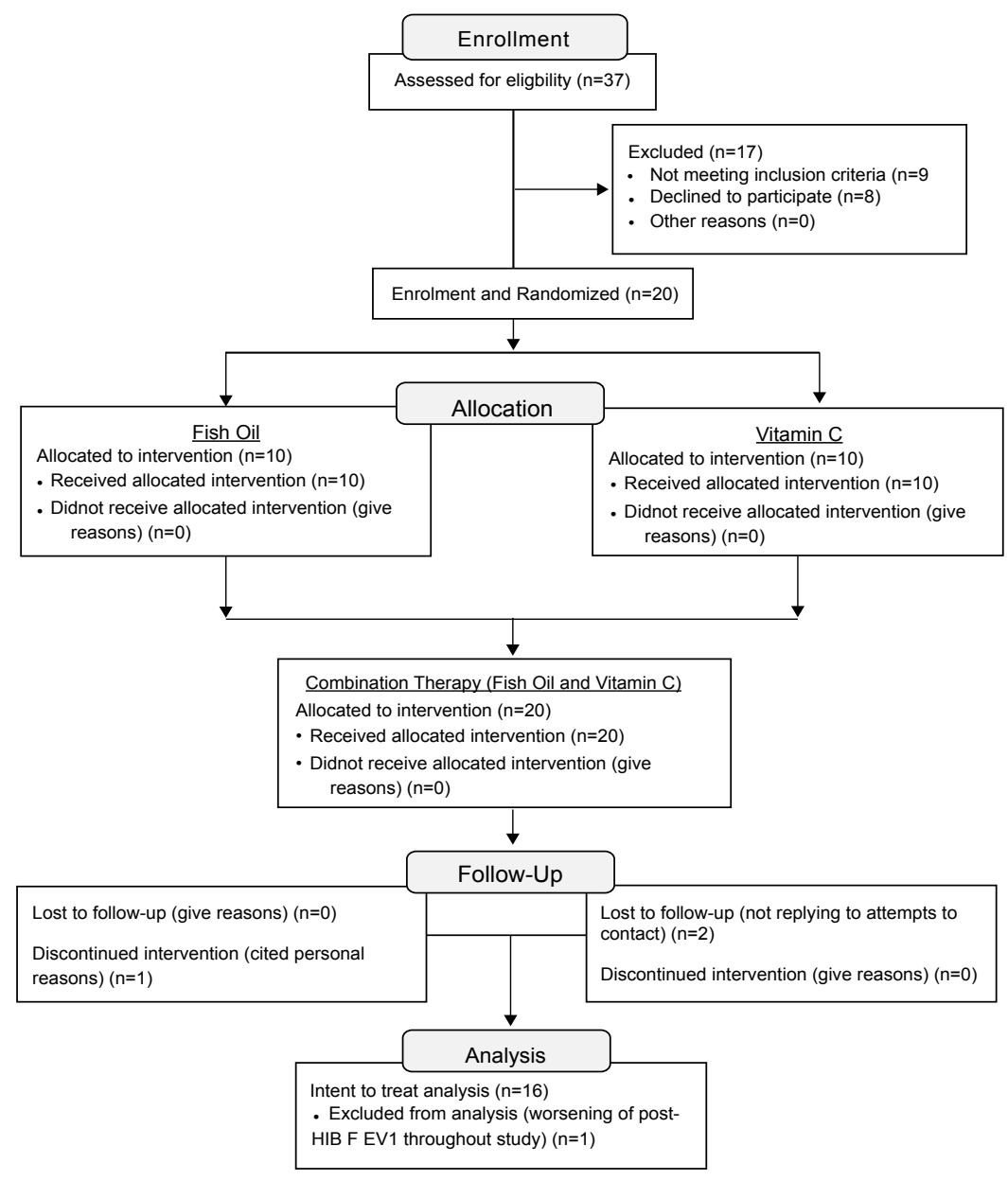

Figure 1: CONSORT flow of participants through the study diagram. 
included in this study design as it has been previously reported that fish oil supplementation does not significantly affect pulmonary function or inflammatory mediators in individuals without asthma or EIB [8]. Subjects were not allowed to take asthma maintenance medications during the study other than their prescribed short-acting $\beta 2$-agonists (e.g. albuterol), which could be used ad libitum except for 12 hours prior to reporting to the laboratory for testing. In addition, subjects reported to the laboratory having abstained from exercise for 24 hours and caffeine/alcohol for 8 hours respectively prior to the laboratory tests.

One subject ceased taking their maintenance medication (fluticasone propionate and salmeterol), with physician approval 4 weeks before starting the study; no other subjects were taking asthma maintenance medications at the time of enrollment. Subjects were asked not to take nutritional supplements containing vitamin $\mathrm{C}$ or fish oil at the time of enrollment or during the study. Subjects were instructed to limit their fish consumption to one meal per week and to avoid vitamin $\mathrm{C}$ rich foods for the duration of the study. Exclusion criteria for the study included pregnancy or a history of diabetes, hypertension, hyperlipidemia, bleeding disorders, delayed clotting time, or seizures. The study was approved by the Indiana University Institutional Review Board (protocol \# 0910000751) and was registered as a clinical trial with clinicaltrials.gov (study \# NT01057615). Written informed consent was obtained from all subjects prior to enrollment.

\section{Study design}

This study was conducted a randomized, double-blind, parallel group, placebo-controlled trial over the course of 3 weeks followed by a single group trial (both groups combined) for a further 3 weeks. Each subject underwent a 2 -week run-in period preceding the trial when baseline measures (usual diet) were performed. Testing was conducted during the run-in period and at the conclusion of each 3-week treatment period, and at the end of the 2-week washout period.

Subjects entered the study on their usual diet $(n=16)$ (phase 1) and then were randomly divided into one of two groups. The two parallel treatment groups (phase 2) consisted of either vitamin C capsules containing a total of $1500 \mathrm{mg}$ of pharmaceutical grade ascorbic acid (NOW Foods, Bloomingdale, IL) and placebo fish oil capsules containing soybean oil $(n=8)$ taken daily, or placebo vitamin $\mathrm{C}$ capsules containing sucrose and active pharmaceutical grade fish oil capsules (Nordic Naturals, Watsonville, CA) containing a total of 3.2 g EPA and 2.0 g DHA taken daily $(n=8)$. Subjects then underwent a 2 -week washout period where they did not take any capsules. After the washout period, all subjects $(n=16)$ took both the active vitamin $C$ and fish oil capsules for a further 3 weeks (phase 3 ).

An independent investigator having no contact with the subjects and no involvement in data collection or analysis used a computerized random number generator (http://www.randomizer.org/form.htm) to create the randomization sequence which was stratified by sex with a 1:1 allocation using a fixed random blocks size of two. The active fish oil and ascorbic acid capsules were identical in appearance to their respective placebo counterpart. Identical packages of capsules were numbered by the independent investigator. After the principal investigator obtained the subject's consent, the independent investigator was asked to provide the allocation assignment for the subject. A list of subject numbers and randomized allocation numbers were kept confidential by the independent investigator, and revealed to the principal investigator only after data collection and initial data analysis were completed.
Bronchoprovocation was elicited with the aid of a eucapnic voluntary hyperventilation (EVH) test at the end of phase 1,2 and 3. Prior to, and following the EVH test, the fraction of exhaled nitric oxide (FENO), exhaled breath condensate (EBC) pH (FENO and EBC $\mathrm{pH}$ are non-invasive markers of airway inflammation) and pulmonary function were measured in that order. Subjects were asked to record daily peak flow, short-acting $\beta 2$-agonist use, and asthma symptoms scores daily throughout the course of the study. Two 24-hour dietary recalls were conducted during each 3 week phase of the study to gauge any changes in nutrient intake over the course of the study. Compliance with supplementation was assessed by counting the pills returned by the subjects at their second and third laboratory tests.

\section{Eucapnic voluntary hyperventilation}

The EVH challenge, which requires subjects to breathe cold, dry air at a rapid rate, is the preferred method that the International Olympic Committee recommends for identifying athletes with EIB [19]. Subjects were asked to breathe, while wearing nose clips, through a non-rebreathing two-way valve (Hans Rudolph, Inc., Kansas City, $\mathrm{MO})$ connected to a reservoir bag continually filled with $21 \%$ oxygen, $5 \%$ carbon dioxide, and balance nitrogen from a compressed gas tank containing less than $3 \mathrm{mg} \mathrm{H}_{2} \mathrm{O}_{\mathrm{L}}{ }^{-1}$ air [10]. Subjects were instructed to breathe for 6 minutes at $85 \%$ of their maximal voluntary ventilation as estimated by $30 \mathrm{x}$ their resting FEV1 [19]. In order to verify the ventilatory rate, the investigator continuously monitored each subjects' ventilation rate during the EVH challenge (Vmax 22 Metabolic Measurement Cart, SensorMedics, Yorba Linda, CA).

\section{Pulmonary function tests}

Pulmonary function was measured pre-EVH and post-EVH at 5, 10, 15 , and 20 minutes using a calibrated computerized pneumotachograph spirometer (Vmax 22 Metabolic Measurement Cart, SensorMedics, Yorba Linda, CA). In accordance with American Thoracic Society recommendations [21], at all pre- and post-EVH time points each subject performed three acceptable spirograms, of which the largest and second largest forced vital capacity (FVC) and FEV1 values did not vary by more than $0.15 \mathrm{~L}$ [22], and the best FEV1 and FVC maneuver kept for analysis. The maximum percentage fall in FEV1 for the baseline (pre-EVH) was calculated using the following equation: (PreEVH FEV1-lowest post-EVH FEV1)/(Pre- EVH FEV1). In addition, the bronchoconstrictor response to the EVH airway challenge was assessed as the area under the curve of the percent fall in post-EVH FEV1 plotted against time for 20 min (AUC0-20) using trapezoidal integration.

\section{Fraction of exhaled nitric oxide}

Before and following the EVH challenge, the measurement of the fraction of exhaled nitric oxide (FENO) was recorded using a restricted exhaled breath protocol (NOA 280i Nitric Oxide Analyzer, Accurate NO Breath Kit, Thermal Mass Flowmeter, NO Analysis Software Version 3.21, Sievers Instruments, Boulder, CO) following ATS guidelines [23]. Accordingly, subjects were instructed to inhale maximally to their total lung capacity and immediately exhale against expiratory resistance at a rate of $50 \pm 10 \mathrm{~mL} / \mathrm{s}$ for at least 6 seconds to produce a nitric oxide plateau lasting at least 3 seconds; real time feedback was provided visually on a computer screen. Subjects performed this maneuver while wearing nose clips with at least 30 seconds of rest between each trial [10]. The FENO was recorded as the mean of three exhalations with the individual FENO values within $10 \%$ of the mean FENO [23]. 


\section{Exhaled breath condensate $\mathrm{pH}$}

EBC samples were collected with a specially designed condensing chamber (ECoscreen, Jaeger, Hoechberg, Germany) using ATS/ERS guidelines [24]. The EBC protocol required subject to wear nose clips, and to breathe normally through a mouthpiece connected to a nonrebreathing valve, whereby exhaled breath entered a condenser system, which was set at a temperature of $-20^{\circ} \mathrm{C}$, providing immediate sample freezing. Exhaled breath was collected for $10 \mathrm{~min}$ prior to and intervals (1-10 min) following the EVH challenge. The $\mathrm{pH}$ of the non-deaerated EBC was measured immediately following collection with an Orion2 star $\mathrm{pH}$ meter (Thermo Scientific, Beverly, CA). It has been shown that $\mathrm{EBC} \mathrm{pH}$ measurements collected by the ECoScreen are repeatable and reproducible [25].

\section{Symptoms, short-acting $\beta 2$-agonist use and peak flow measurements}

Subjects were instructed to rate their asthma symptoms by filling out a symptoms diary every day throughout the study. This diary was adapted from Santanello et al. [26] and contained four questions concerning daytime symptoms with a 7-point scale and one question concerning nighttime symptoms with a 4-point scale. Symptom scores were calculated for each subject by averaging the mean score from each day [26]. Subjects were asked to record their short-acting $\beta 2$-agonist use (rescue medication) by marking down the number of puffs taken per day throughout the duration of the study in log books provided to them. Electronic peak flow meters (PiKo-1, Ferraris Medical, Louisville, CO, USA) were given to each subject to measure their morning and evening peak expiratory flow throughout the duration of the study. Subjects were instructed to perform the peak flow maneuver by inhaling fully to total lung capacity and then exhale forcefully through the flow meter according to manufacture instructions. Subjects were instructed to record the best of three trials upon waking and before going to bed.

\section{Nutrient intake and compliance}

To evaluate nutrient intake during the study, 24-hour dietary recall data were collected for each subject using the nutrition data system for research (NDSR) dietary assessment computer program from the Nutrition Coordinating Center at the University of Minnesota (St. Paul, MN) [27]. Subjects were called by telephone twice during each phase of the study to be interviewed about which food and beverages they consumed in the previous 24 -hour period. These telephone calls were made unannounced so that subjects could not change their eating habits in anticipation of the interview. Adherence to the treatment was monitored by asking the subjects to return any unused capsules. For the purpose of the study a compliance of $\geq 90 \%$ was considered acceptable [10].

\section{Data Analysis}

Data was analyzed with SPSS version 18.0 statistical software (SPSS Inc., Chicago, IL). Normality of data was assessed using a KolmogorovSmirnov test and Levene's test was used to check for homogeneity of variance between groups. A repeated measures analysis of variance (ANOVA) was used to analyze the data (within-subject) at baseline $(n=16)$ and for the single $(n=8)$ and combination treatment $(n=16)$. Mauchley's test was conducted to determine if sphericity was violated; if it was, the repeated measures ANOVA was corrected using a Greenhouse-Geisser adjustment factor. Pairwise comparisons, with a Bonferroni adjustment (used to maintain an overall type-I error rate of $5 \%$ ) were used to isolate differences in group means; this was accomplished by dividing the probability value by the number of pairwise comparisons, and thus significance was held at $\mathrm{p} \leq 0.017$. As a check, differences between the usual diet and the combination treatment values were analyzed using a paired t-test (one-tailed) with a Bonferroni adjustment made to the $\mathrm{p}$-value $(\mathrm{p}<0.017)$ to account for the multiple tests, while an unpaired t-test was used to analyze differences between the two single treatment arms. The Wilcoxon signed rank test was used to compare symptom scores and bronchodilator use during the trial. Data are expressed a mean \pm SD, and their $95 \%$ confidence interval (CI).

A statistical power analysis was used to determine the number of subjects required to show a significant difference between groups. In separate studies, we have previously examined the efficacy of fish oil or ascorbic acid supplementation on airway inflammation and EIB $[10,18]$. Based on the maximum percent drop in FEV1 following an exercise challenge in these subjects, it was determined, with the aid of the $\mathrm{G}^{*}$ Power 3.0.5 program (Universität Kiel, Germany), that a minimum of 7 subjects per group would be needed to show a significant difference between baseline (usual diet) and post-supplementation pulmonary function for a statistical power of 0.80 . Since it was hypothesized that the combination treatment would be more effective than either intervention alone, it was expected that fewer subjects would be needed to show a significant difference.

\section{Results}

\section{Subjects}

Bronchodilator use (average number of puffs/doses taken per day) was significantly reduced on the fish oil diet $(0.03 \pm 0.08$ puffs $)$ compared to the usual diet $[0.94+1.2$ puffs; $p=0.005$; (mean difference), $1.0 \pm 1.2$ puffs; $95 \%$ CI, 0.005 to 2.0 puffs], and significantly reduced on the vitamin $\mathrm{C}$ diet $(0.08 \pm 0.18$ puffs $)$ compared to the usual diet ( $\mathrm{p}=0.008 ; \Delta, 0.74 \pm 1.2$ puffs; $95 \% \mathrm{CI}, 0.12$ to 2.2 puffs). In addition, bronchodilator use was significantly reduced on the combination therapy $(0.08 \pm 0.13$ puffs) compared to the usual diet ( $\mathrm{p}=0.004 ; 0.86$ \pm 1.2 puffs; $95 \%$ CI, 0.214 to 1.497 puffs]. However, no significant differences were $(p>0.017)$ observed between the usual diet and vitamin $\mathrm{C}$ diet $(0.09 \pm 0.18$ puffs $)$, or between the three interventional diets $(\mathrm{p}>0.017)$.

A significant improvement in mean asthma symptom scores during the 3 week treatment periods was observed on the fish oil diet $(0.81+0.5 ; \mathrm{p}=0.005 ; \Delta, 0.57+0.96 ; 95 \% \mathrm{CI}, 0.02$ to 1.37$))$, vitamin $\mathrm{C}$ diet $(0.87 \pm 0.5 ; \mathrm{p}=0.008 ; \Delta, 1.2 \pm 1.3 ; 95 \% \mathrm{CI}, 0.008$ to 2.37$)$ and combination therapy $(0.92 \pm 0.67 ; \mathrm{p}=0.011 ;, 0.74 \pm 1.3 ; 95 \% \mathrm{CI}, 0.043$ to 1.43$))$ compared to the usual diet $(1.65 \pm 0.93)$. However, there was no significant difference ( $p>0.017)$ between mean asthma symptoms scores between the three interventional diets.

No significant differences $(\mathrm{p}>0.017)$ were found in morning or evening peak flow [(morning: $432.6+38.7 \mathrm{~L} / \mathrm{min}$; usual diet; $439.6+$ $35.4 \mathrm{~L} / \mathrm{min}$, fish oil diet; $443.7 \pm 36.7 \mathrm{~L} / \mathrm{min}$, vitamin $\mathrm{C}$ diet; and $456.2+$ $34.9 \mathrm{~L} / \mathrm{min}$, combination therapy) (evening: $437.2+39.7 \mathrm{~L} / \mathrm{min}$; usual diet; $454.2+32.5 \mathrm{~L} / \mathrm{min}$, fish oil diet; $451.4 \pm 36.8 \mathrm{~L} / \mathrm{min}$, vitamin $\mathrm{C}$ diet; and $443.6 \pm 34.1 \mathrm{~L} / \mathrm{min}$, combination therapy)].

\section{Pulmonary function and ventilation rate during EVH}

There was no significant difference $(p>0.017)$ between groups (usual diet, fish oil supplementation, vitamin $\mathrm{C}$ supplementation or combination treatment) in baseline (pre-EVH) pulmonary function (Table 1). The maximum percent fall in post-EVH FEV1, FVC and FEF25-75\% as a result of diet are shown in Figures 2-5 respectively. 
Citation: Mickleborough TD, Lindley MR (2014) The Effect of Combining Fish Oil and Vitamin C on Airway Inflammation and Hyperpnea-Induced Bronchoconstriction in Asthma. J Allergy Ther 5: 184. doi:10.4172/2155-6121.1000184

Page 5 of 10

\begin{tabular}{|c|c|c|c|c|}
\hline \multicolumn{5}{|c|}{ Treatment } \\
\hline & $\begin{array}{l}\text { Usual Diet } \\
\quad(n=16)\end{array}$ & $\begin{array}{c}\text { Fish oil } \\
(n=8)\end{array}$ & $\begin{array}{c}\text { Vitamin C } \\
(n=8)\end{array}$ & $\begin{array}{c}\text { Combination } \\
(n=16)\end{array}$ \\
\hline $\begin{array}{l}\text { FVC (L) } \\
\% \text { predicted }\end{array}$ & $\begin{array}{c}4.58 \pm 0.84 \\
104.26 \pm 17.8\end{array}$ & & & \\
\hline $\begin{array}{c}\mathrm{FEV}_{1}(\mathrm{~L}) \\
\% \text { predicted }\end{array}$ & $\begin{array}{l}3.78 \pm 0.48 \\
98.7 \pm 13.6\end{array}$ & & & \\
\hline $\begin{array}{l}\mathrm{FEF}{ }_{25-75 \%}(\mathrm{~L} / \mathrm{min}) \\
\% \text { predicted }\end{array}$ & $\begin{array}{l}3.62 \pm 0.67 \\
82.3 \pm 18.6\end{array}$ & $\begin{array}{l}3.43 \pm 0.59 \\
79.4 \pm 17.4\end{array}$ & $\begin{array}{l}3.58 \pm 0.76 \\
86.9 \pm 21.4\end{array}$ & $\begin{array}{l}3.62 \pm 0.65 \\
83.6 \pm 18.1\end{array}$ \\
\hline FEV $_{1} /$ FVC (\%) & $79.4 \pm 8.2$ & $81.1 \pm 6.3$ & $80.5 \pm 5.7$ & $82.7 \pm 6.9$ \\
\hline
\end{tabular}

Definitions of abbreviations: FVC, forced vital capacity; $\mathrm{FEV}_{1}$, forced expiratory volume in $1-\mathrm{s} ; \mathrm{FEF}_{25-75 \%}$, forced expiratory flow at $25-75 \%$ of $\mathrm{FVC}$. Values reported are mean $\pm S D$. There was no significant difference $(p>0.017)$ for pulmonary function values between diets.

Table 1: Pre- hyperpnea (baseline) pulmonary function.

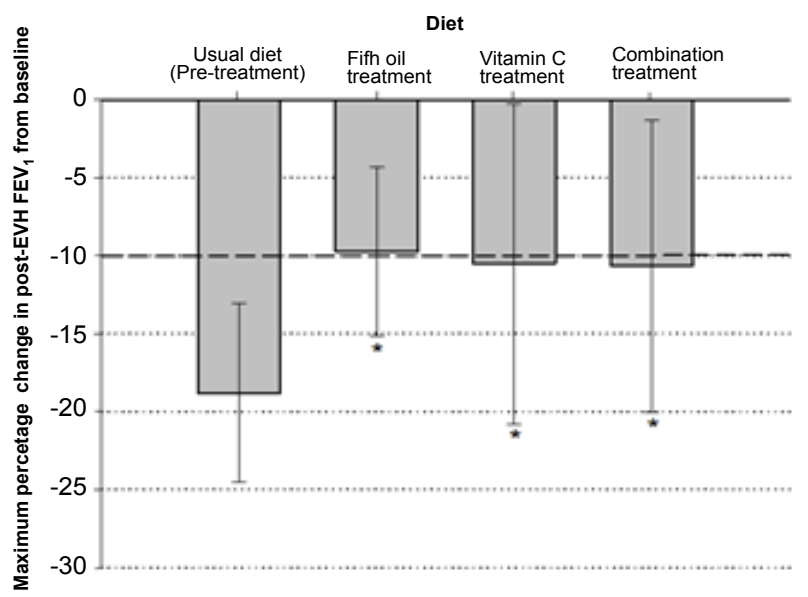

*Significantly different $(p<0.013)$ compared to usual diet. There was no significant difference $(p>0.013)$ between the three treatment diets. There was no significant difference $(p>0.013)$ between the three treatment diets for the maximum percent change in FEV1 from pre-to post-EVH. Values are mean \pm SD.

Figure 2: The maximum percent change in FEV1from pre-to post-EVH for the * Significantly different $(p<0.013)$ compared to usual diet. There was no significant difference $(p>0.013)$ between the three treatment diets. There was no significant difference ( $p>0.013)$ between the three treatment diets for the maximum percent change in FEV1 from pre-to post-EVH. Values are mean+SD. usual diet and the threetreatment diets. Reductions in post-EVH in excess of $10 \%$ represent abnormal pulmonary function.

Prior to the treatment interventions (usual diet), the maximum percent drop in post FEV1, FVC and FEF25-75\% was $18.8 \pm 5.7 \%, 11.2 \pm$ $6.6 \%$ and $33.6 \pm 11.1 \%$ respectively. However, there was a significant reduction $(\mathrm{p}<0.017)$, compared to the usual diet, in the maximum percent drop in post-EVH FEV1, FVC and FEF25-75\% to $9.7 \pm 5.4 \%$ ( $\mathrm{p}=0.016 ; \Delta,-7.6 \pm 8.2 \% ; 95 \% \mathrm{CI},-14.5$ to- $0.8 \%)$, to $4.5 \pm 2.5 \%$ ( $\mathrm{p}=0.016$; $\Delta,-6.4 \pm 6.8 \%, 95 \% \mathrm{CI},-12.7$ to- $0.7 \%)$ and to $18.3 \pm 9.8 \%(\mathrm{p}=0.005 ; \Delta,-$ $10.6 \pm 8.6 \%$; $95 \%$ CI, -17.8 to- $3.4 \%$ ) respectively on the fish oil diet, to $10.5 \pm 10.2 \%(\mathrm{p}=0.016 ; \Delta,-9.8 \pm 10.5 \% ; 95 \% \mathrm{CI},-18.6$ to -1.1$)$, to 5.1 $\pm 4.3 \%(\mathrm{p}=0.014 ; \Delta, 6.3 \pm 6.5 \% ; 95 \% \mathrm{CI},-11.7$ to- $0.9 \%)$ and to $18.2 \pm$ $13.1 \%(\mathrm{p}=0.015 ; \Delta,-20.1 \pm 21.0 \% ; 95 \% \mathrm{CI},-37.7$ to $-2.5 \%)$ respectively on the vitamin $\mathrm{C}$ diet, and to $10.7 \pm 9.3 \%$ ( $\mathrm{p}=0.007 ; \Delta,-8.1 \pm 11.7 \%$; $95 \%$ CI,-14.4 to-1.9\%), to $4.1 \pm 3.1 \%(\mathrm{p}=0.0006 ; \Delta,-7.1 \pm 7.2 \%$; $95 \% \mathrm{CI},-10.9$ to-3.3\%) and to $20.1 \pm 14.1 \%$ ( $\mathrm{p}=0.006 ; \Delta,-13.5 \pm 18.8 \%$; $95 \%$ CI, -23.5 to-3.5\%) respectively on the combination treatment. However, there was no significant difference $(p>0.017)$ in the maximum percent drop in postEVH FEV1, FVC and FEF25-75\% between the treatment groups.

The bronchoconstrictor response to $\mathrm{EVH}$ as determined by the AUC0-20 for FEV1 was significantly greater $(\mathrm{p}<0.017)$ for pretreatment (usual diet) $(352.8 \pm 42.4)$ compared with the fish oil diet $(227.3 \pm 39.6 \%$.min; $\mathrm{p}=0.002 ;, 126.0 \pm 38.7 \%$.min ; $95 \% \mathrm{CI}, 98.4$ to $176.4 \% . \mathrm{min})$, vitamin $\mathrm{C} \operatorname{diet}(247.5 \pm 43.6 \% \cdot \mathrm{min} ; \mathrm{p}=0.001 ; \Delta, 105 \pm$ $41.7 \%$.min; $95 \%$ CI, 74.6 to $147.8 \%$.min), and combination treatment $(218.4 \pm 48.9 \%$.min; $\mathrm{p}=0.004 ; \Delta, 134.1+43.9 \%$ min; $95 \% \mathrm{CI}, 102.6$ to $184.7 \%$.min). However, no significant difference $(\mathrm{p}>0.017)$ between the three post-treatment groups was observed for AUC0-20 postEVH FEV1. Minute ventilation during each of the four EVH trials did not significantly differ $(\mathrm{p}>0.05)$ between diet [usual diet: $81.1+10.6$ $\mathrm{L} / \mathrm{min}(61.1 \pm 10.9 \% \mathrm{MVV})$; fish oil diet: $83.4 \pm 12.5 \mathrm{~L} / \mathrm{min}(62.7 \pm$ $11.0 \% \mathrm{MVV})$; Vitamin C diet: $86.1 \pm 12.2 \mathrm{~L} / \mathrm{min}(64.8 \pm 6.5 \% \mathrm{MVV})$; Combination treatment: $79.2 \pm 11.7 \mathrm{~L} / \mathrm{min}(60.2+11.5 \% \mathrm{MVV})$.

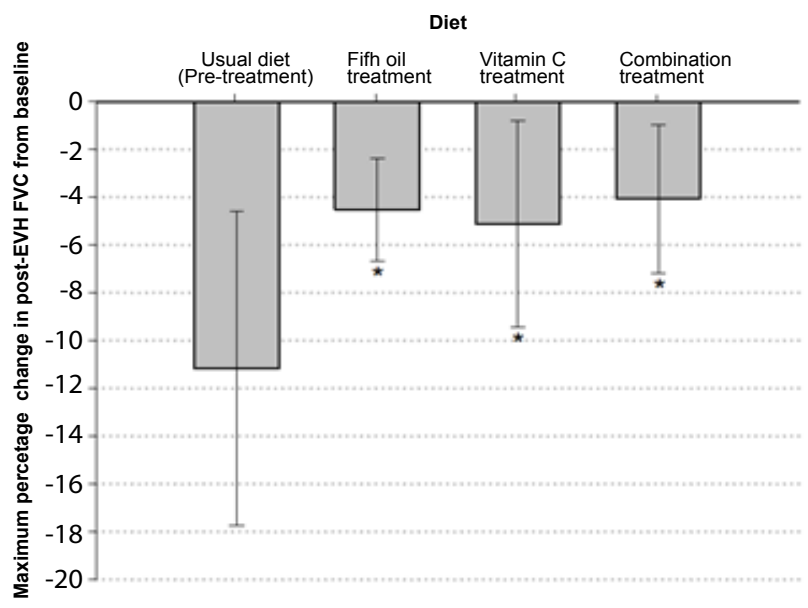

Figure 3: The maximum percent change in FVC from pre-to post-EVH for the usual diet and the threetreatment diets. * Significantly different $(p<0.013)$ compared to usual diet. There was no significant difference $(p>0.013)$ between the three treatment diets. There was no significant difference $(p>0.013)$ between the three treatment diets for the maximum percent change in FVC from pre-to post-EVH. Values are mean \pm SD.

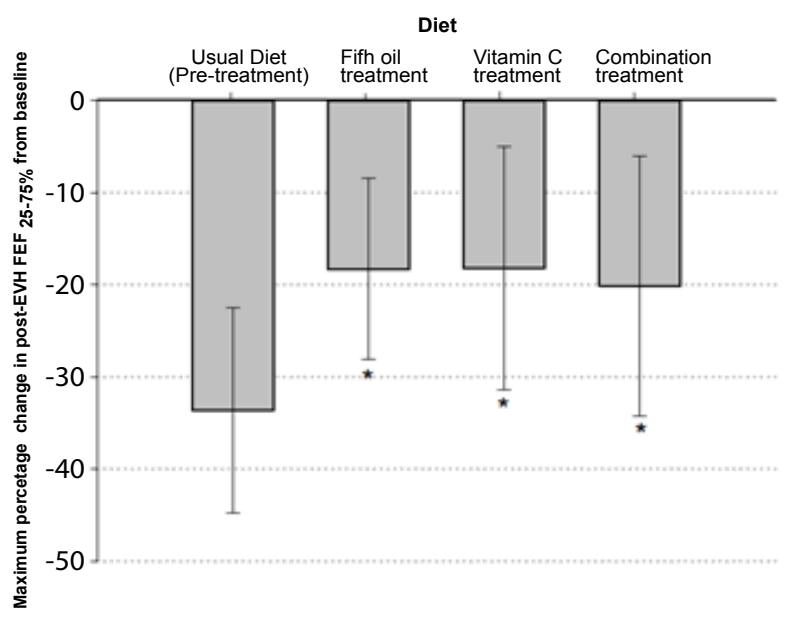

Figure 4: The maximum percent change in FEF25-75\% from pre-to post-EVH for the usual diet and thethree treatment diets. *Significantly different $(p<0.013)$ compared to usual diet. There was no significant difference $(p>0.013)$ between the three treatment diets for the maximum percent change in FEF25-75\% from pre- to post-EVH. Values are mean \pm SD. 


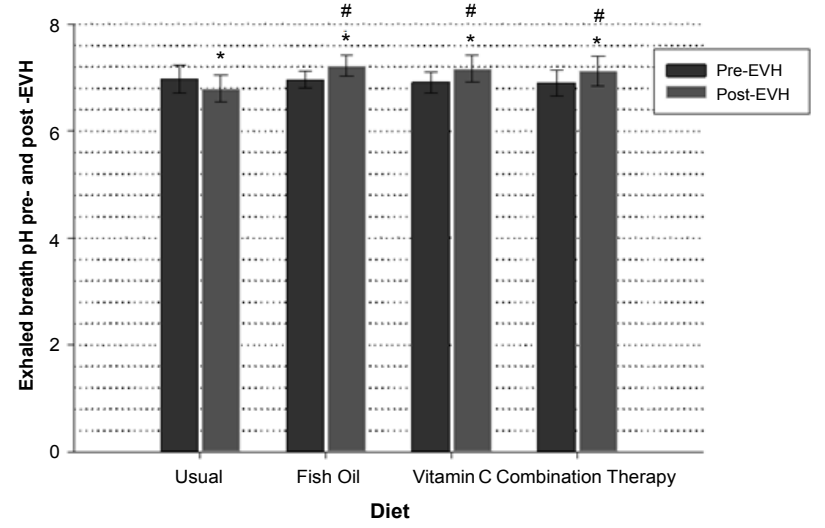

Figure 5: Mean exhaled breath condensate (EBC) $\mathrm{pH}$ pre- and post-EVH *Significantly different $(p<0.013)$ to pre-EVH value within diet. \#Significantly different $(p<0.013)$ to usual diet post-EVH. There was no significant difference $(p>0.013)$ between the three treatment groups for pre- or post-EVH EBC $\mathrm{pH}$.Values are mean $\pm \mathrm{SD}$.

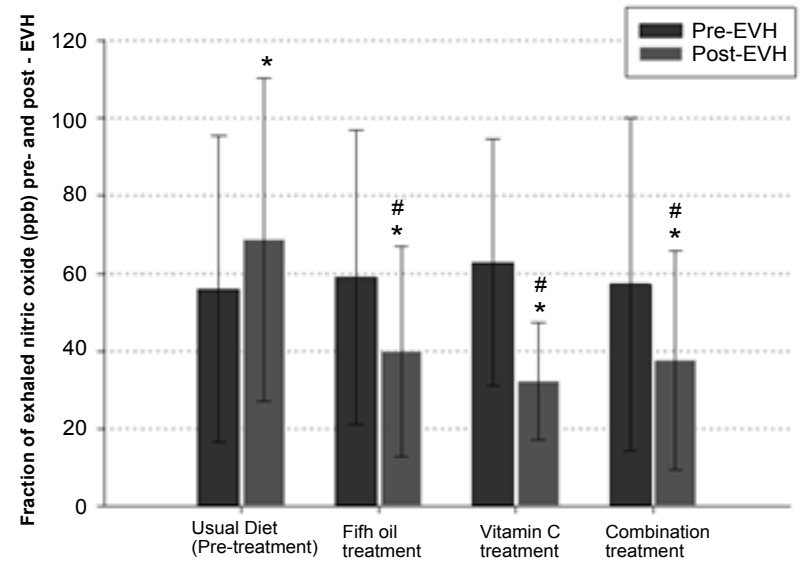

Diet

Figure 6: Mean fraction of exhaled nitric oxide (FENO) concentration (ppb) pre- and post-EVH. *Significantly different $(p<0.013)$ to pre-EVH value within diet. "Significantly different $(p<0.013)$ to usual diet post-EVH. There was no significant difference $(p>0.013)$ between the three treatment groups for pre- or post-EVH FENO. Values are mean \pm SD.

\section{Exhaled breath condensate $\mathrm{pH}$ and fraction of exhaled nitric oxide}

There was no significant difference $(p>0.017)$ between the dietary groups for pre-EVH EBC $\mathrm{pH}$. However, there was a significant difference between the pre- and post-EVH EBC $\mathrm{pH}$ values for the usual $\operatorname{diet}(\mathrm{p}=0.009 ;-0.18 \pm 0.30 ; 95 \% \mathrm{CI},-0.016$ to- 0.33$)$, fish oil diet $(\mathrm{p}=0.006$; , $+2.23+0.26 ; 95 \% \mathrm{CI}, 0.47$ to 0.045$)$, vitamin $\mathrm{C} \operatorname{diet}(\mathrm{p}=0.012 ; \Delta,+0.25$ \pm 0.3 ; $95 \%$ CI, 0.50 to -0.0031 ), and combination treatment ( $\mathrm{p}=0.006$; , $+0.22 \pm 0.34 ; 95 \%$ CI, 0.40 to 0.035 ) (Fig. 5). In addition, there was a significant difference $(\mathrm{p}<0.017)$ between the usual diet post-EVH $\mathrm{EBC} \mathrm{pH}$ and the post-EVH EBC $\mathrm{pH}$ for the fish oil diet ( $\mathrm{p}=0.002 ; \Delta$, $+0.42 \pm 0.32 ; 95 \% \mathrm{CI}, 0.69$ to 0.15$)$, vitamin $\mathrm{C} \operatorname{diet}(\mathrm{p}=0.011 ; \Delta,+0.38$ $\pm 0.44 ; 95 \% \mathrm{CI}, 0.75$ to 0.010$)$, and combination treatment $(\mathrm{p}=0.0013$; $\Delta,+0.326 \pm 0.40 ; 95 \% \mathrm{CI}, 0.54$ to 0.114 ). There were no significant differences ( $p>0.017)$ between the fish oil diet, vitamin $\mathrm{C}$ diet and combination treatment for post-EVH EBC $\mathrm{pH}$ values.
The pre-EVH FENO was not significantly different $(p>0.017)$ between diets. However, there was a significant difference $(\mathrm{p}<0.017)$ between the pre- and post-EVH FENO for the usual diet ( $\mathrm{p}=0.007 ; \Delta$, $+12.8 \pm 32.2$; $95 \% \mathrm{CI}, 30.6$ to 5.1 ), fish oil diet ( $\mathrm{p}=0.003 ; \Delta,-19.1+$ $33.3 ; 95 \% \mathrm{CI},-4.7$ to-47.0), vitamin $\mathrm{C} \operatorname{diet}(\mathrm{p}=0.006 ; \Delta,-30.7 \pm 27.9 ; 95 \%$ CI, -4.8 to-56.5), and combination treatment ( $\mathrm{p}=0.002$, , $-19.7 \pm 24.6$; 95\% CI,-6.0 to -33.3) (Figure 6). Furthermore, there was a significant difference $(p<0.017)$ between the usual diet post-EVH FENO and the post-EVH FENO for the fish oil diet $(\mathrm{p}=0.009 ; \Delta,-22.5 \pm 49.1 ; 95 \%$ CI,-12.1 to-63.5), vitamin $\mathrm{C}$ diet ( $\mathrm{p}=0.011 ; \Delta,-43.8 \pm 44.6 ; 95 \% \mathrm{CI},-2.6$ to-85.1), and combination treatment $(\mathrm{p}=0.005 ; \Delta,-31.2 \pm 46.0 ; 95 \%$ CI,-5.7 to-56.7). No significant differences ( $\mathrm{p}>0.017)$ were observed for post-EVH FENO values between the fish oil diet, vitamin $\mathrm{C}$ diet and combination treatment.

\section{Nutrient intake and compliance}

Subject compliance to the treatments was assured by finding that pill counts conducted at the end of each treatment period reflected that capsules were consumed on a regular basis. Compliance as estimated from return-tablet count was high (median, 99\%). Whilst the usual diet was expected to vary between subjects, mean daily nutrient intake [i.e. total carbohydrate $(\mathrm{g})$, total protein $(\mathrm{g})$, total dietary fiber $(\mathrm{g})$, vitamin C (mg) vitamin E (mg), lycopene (mcg), arachidonic acid $(\mathrm{g})$, EPA (g), DHA (g), linoleic acid (g), linolenic acid (g) sodium ( $\mathrm{mg}$ ), zinc (mg), selenium (mcg), and caffeine (mg)] of the subject's diet did not significantly differ $(p>0.05)$ during the course of the study between the treatment regimens.

\section{Discussion}

To our knowledge this is the first study to investigate the effectiveness of a "polypill approach" (several nutrients in combination) versus a single nutrient approach on airway inflammation and HIB in asthmatic individuals. The present study has shown that a diet supplemented with fish oil or vitamin $\mathrm{C}$ were both effective in attenuating the bronchoconstrictor response to dry gas hyperpnea and airway inflammation in asthmatic patients. However, when these two nutrients were combined no further reduction in HIB or airway inflammation was observed. All three treatments significantly reduced short-acting $\beta 2$-agonist use and asthma symptoms, reduced airway hyperresponsiveness as evidenced by a reduction in FEV1, FVC and FEF25-75\% post-EVH, and reduced the severity of HIB as measured by the AUC0-20. Fish oil and vitamin $\mathrm{C}$ supplementation taken in isolation, and combined, significantly reduced the maximum fall in post-EVH FEV1 by approximately $48.3 \%, 43.5 \%$ and $43.3 \%$ respectively, by approximately $59.7 \%, 54.1 \%$ and $63.7 \%$ respectively for FVC, and by $45.5 \%, 45.8 \%$ and $40.2 \%$ respectively for FEF $25-75 \%$. The degree of protection provided by the fish oil supplementation in the present study is similar in magnitude to a previous study from our group [10] that demonstrated that 3 weeks of fish oil, rich in the omega-3 fatty acids eicosapentaeoic acid (EPA) and docosahexaenoic acid (DHA), reduced the maximum drop in post-EVH FEV1 by approximately $49 \%$ in asthmatic subjects with HIB. The protective effect of fish oil supplementation on the bronchoconstrictor response in the present study is also similar in magnitude to a recent study [9] that demonstrated that a patented extract of stabilized lipids from the New Zealand Green Lipped Mussel, P. canaliculus, which contains up to 91 fatty acids including EPA and DHA [28], reduced the maximum fall in post-EVH FEV1 by approximately $57 \%$. In addition, in the present study, the degree of protection provided by the vitamin $\mathrm{C}$ supplementation on the post-EVH FEV1 $(\sim 43.5 \%)$ is similar in 
magnitude to a previous report from our group [18] that showed approximately a $50 \%$ improvement in post-exercise FEV1 in asthmatic subjects following 2 weeks of vitamin C supplementation.

Airway $\mathrm{pH}$ is an important determining factor of the FENO and airway inflammation, and there may be a casual association between airway acidification and airflow limitation in asthma, such that the regulation of airway $\mathrm{pH}$ may play an important role in asthma/EIB pathophysiology [29]. EBC $\mathrm{pH}$ is lower in asthmatic individuals and correlates positively with sputum eosinophilia, total nitrate/nitrite and oxidative stress [30]. The acidic EBC $\mathrm{pH}$ documented in asthmatics tends to normalize with anti-inflammatory therapy [29], which supports the findings of the present study, and our previous reports $[9,10]$, that a diet supplemented with omega-3 fatty acids can alkalize EBC (airway) $\mathrm{pH}$ in asthmatics, and in the present study the novel finding that vitamin $\mathrm{C}$ supplementation can also restore the post-EVH $\mathrm{EBC} \mathrm{pH}$ to baseline (pre-EVH) values on the usual diet.

In the present study all three treatments reduced the FENO concentration post-EVH indicating attenuation in airway inflammation. Previous studies have shown that FENO can be used as an indirect marker of asthmatic airway inflammation [31], and have shown a relationship between FENO levels and EIB [32]. Previous works by Schubert et al. [33] and our group $[9,10]$ has shown that omega-3 fatty acid supplementation can reduce FENO levels in patients with atopic asthma and HIB respectively. Likewise, we have previously shown [18] that 2 weeks of $1500 \mathrm{mg} /$ day of vitamin C supplementation can mitigate FENO levels in asthmatic subjects with EIB.

EPA and DHA can both influence inflammatory signaling by causing dual inhibition of the cyclooxygenase-2 (COX-2) and 5-lipoxygenase (5-LO) pathways for metabolism of arachidonic acid (AA). It has been shown that 5-LO product formation in the lung capillary bed is critically dependent on intravascular precursor fatty acid supply, with EPA representing the preferred substrate compared with AA [34]. EPA can inhibit release of AA derived eicosanoids, such as pro-inflammatory 4-series leukotrienes (LTs) and 2-series prostaglandins (PGs), and cytokines from airway inflammatory cells [35], and be metabolized to the less potent 5-series LTs and 3-series PGs [34]. Eosinophil's, mast cells, basophils, and alveolar macrophages have all been shown to directly synthesize the 4-series CysteinylLTs, which can increase vascular permeability and contract smooth muscle cells, causing bronchoconstriction, and may directly increase eosinophilic airway inflammation [7]. Although DHA may have similar anti-inflammatory effects as EPA, it does not act by direct competition with AA. DHA can decrease the release of AA from membrane phospholipids by decreasing phospholipase A2 activity [36], and decreasing the responsiveness of toll-like receptor-4 to LPS, thereby suppressing nuclear factor-kappaB activation and subsequent inflammatory gene transcription [37].

Along with their direct effect on AA metabolism, EPA, DHA and AA can be transformed into a variety of inflammatory mediators, termed oxylipins, and which involve a number of enzymatic pathways, including 5-, 12-, and 15-LO, COX-2, cytochrome P450 and soluble epoxide hydrolase. EPA is a precursor to the E-series of inflammatory resolution phase products (resolvins), which have potent antiinflammatory properties, with RvE1 having beneficial effects in a murine model of asthma $[38,39]$. The anti-inflammatory DHA-derived lipid mediators include the $\mathrm{D}$-series resolvins (RvD1-4), docosatrienes and protections [13]. Levy et al. [40] have shown that injecting mice with protectin D1 (PD1) decreased airway hyperresponsiveness, and that adding DHA to homogenized murine lung tissue ex-vivo yields a significant increase in PD1 concentration. In addition, Levy et al. [40] demonstrated that during a human asthma attack patients had significantly lower levels of PD1 in EBC compared to healthy individuals.

Therefore, it appears that increasing membrane EPA and DHA levels will provide an anti-inflammatory benefit in asthma, although each fatty acid may act via different metabolic pathways. The majority of studies investigating the effects of omega-3 fatty acids on asthma/ EIB have either employed fish oils rich in EPA or oils which contain a heterogeneous blend of EPA and DHA. However, we have shown [41] that EPA has a far greater effect than DHA in decreasing the production of pro-inflammatory mediators from human asthmatic alveolar macrophages treated ex vivo, and those 3 weeks of $4.0 \mathrm{~g} / \mathrm{day}$ of DHA supplementation has no effect on airway inflammation or HIB in asthmatic patients [42]. Interestingly, Schuster et al. [43] recently showed that, in a murine model of asthma, a diet enriched with DHA increased airway hyperresponsiveness and airway inflammation compared with a diet enriched with both EPA and DHA.

We have previously shown in elite athletes with EIB [8] that 3 weeks of fish oil supplementation (3.2 g EPA and $2.0 \mathrm{~g}$ DHA per day) increased tissue phospholipid omega- 3 fatty acid concentration, and with a significant suppression of urinary and blood eicosanoids (LTE4, $9 \alpha, 11 \beta$-PGF2, and LTB4, respectively) and pro-inflammatory cytokines (TNF- $\alpha$ and IL-1 $\beta$ ). In a follow-up study [7] we found that sputum differential eosinophil, neutrophil, lymphocyte and macrophage cell counts and sputum supernatant concentrations of pro-inflammatory eicosanoids (LTC4-LTE4 and PGD2), and cytokines (TNF- $\alpha$, IL-1 $\beta$ ) were significantly attenuated, and LTB5 generated from activated polymorphonuclear leukocytes increased, on a 3 week fish oil diet in asthmatic subjects with EIB. In addition, we have shown [10] that 3 weeks of fish oil supplementation can reduce EBC concentrators of cysteinyl-LTs and urinary $9 \alpha, 11 \beta$-PGF2 in asthmatic patients with HIB.

The data from the present study and our previous observations $[7,8,10,41]$ strongly suggest that dietary supplementation with fish oil can suppress airway inflammation in asthmatic subjects, and elite athletes, with EIB and HIB. Of interest, Williams et al. [44] recently published preliminary data, in abstract form, demonstrating that a (low) dose $1.8 \mathrm{~g}$ EPA and $1.3 \mathrm{~g}$ DHA was as effective as a (double) dose of $3.7 \mathrm{~g}$ EPA and $2.5 \mathrm{~g}$ DHA given daily for 3 weeks in attenuating the bronchoconstrictor response to an EVH challenge in EIB subjects.

Previous studies have indicated that there may be a connection between vitamin $\mathrm{C}$ in the diet and asthma. It has been established that asthmatics tend to have lower serum antioxidants, including vitamin $\mathrm{C}$, and that low vitamin $\mathrm{C}$ intake can be associated with asthma severity $[6,45]$, which suggest that asthmatics may have an antioxidant deficiency and/or increased oxidative stress that requires higher levels of reactive oxygen/nitrogen species (ROS/RNS) scavenging antioxidants. In asthma, cytokines released from activated inflammatory cells can initiate ROS/RNS generation by pulmonary macrophages, interstitial cells and leukocytes infiltrating lung tissue [46]. Excess ROS/RNS may overwhelm antioxidant defense, and consequently lead to bronchoconstrictor mediators responsible for EIB. The genes for these inflammatory mediators are regulated by redox-sensitive transcription factors nuclear factor $(\mathrm{NF})$ - kappa $(\kappa)$ $\mathrm{B}$ and activator protein (AP)-1 [47]. NF- $\kappa \mathrm{B}$ has been shown to upregulate the gene for iNOS resulting in increased FENO [48], and has been implicated in the up-regulation of pro-inflammatory cytokines, and the release of pro-inflammatory eicosanoids, such as cysteinyl-LTs 
and prostaglandins [48]. Significantly, it has been demonstrated that vitamin C blocks TNF- $\alpha$ mediated activation of NF- $\mathrm{kB}$ [49].

It has been shown in one study [50] that vitamin C supplementation may have a modest corticosteroid sparing effect in asthmatic patients, and in other studies a decreased bronchial reactivity to methacholine following ascorbic acid supplementation has been observed [51,52]. However, not all studies support these findings in asthmatic patients, with no beneficial effect of ascorbic acid supplementation observed in asthmatics as assessed by spirometry [53], no acute bronchodilator effect following a histamine challenge $60 \mathrm{~min}$ after ascorbic acid supplementation [54], no change in spirometry, airway conductance and antigen-induced bronchospasm following 7 days of supplemental ascorbic acid [55], and no beneficial effect of 16 weeks of ascorbic acid supplementation on pulmonary function, airway responsiveness to methacholine, morning and evening peak flow rates, symptoms scores and bronchodilator use [56]. Indeed, a recent meta-analysis [16] recently concluded that there was not enough evidence to provide a robust assessment on the use of ascorbic acid in the management of asthma. To date, three placebo-controlled interventional studies investigating the effects of vitamin $\mathrm{C}$ on EIB have been published $[18,57,58]$, and the pooled relative effect estimate of these three studies indicates a $48 \%$ reduction ( $95 \%$ CI, $33 \%$ to $64 \%$ ) in the post-exercise FEV1 following vitamin $\mathrm{C}$ supplementation compared to placebo. Thus, it seems plausible that antioxidant supplementation could be effective in reducing the effects of this disease, and there is evidence that vitamin $\mathrm{C}$ plays a role in lung function. Vitamin $\mathrm{C}$ deficiency has been shown to increase the level of the bronchoconstrictor PGF2 [59]. Indomethacin has been shown to antagonize the effect of vitamin $\mathrm{C}$ on methacholine-induced bronchoconstriction in humans [60]. Thus, the effects of vitamin $\mathrm{C}$ may be partially mediated by changes in PG metabolism. We have previously shown [18] that 2 weeks of vitamin $\mathrm{C}$ supplementation ( $1.5 \mathrm{~g} /$ day) can reduce post-exercise FENO and urinary LTC4-E4 and 9a, 11ß-PGF2 concentration, which are both potent bronchoconstrictors.

Many intervention studies in asthma, EIB and HIB have focused on single nutrient supplements, when it is plausible that a combination of nutritional supplements may prove to have a more protective effect. This hypothesis is supported by studies showing protection against ozone-induced bronchoconstriction by a combination of vitamins $\mathrm{C}$ and $\mathrm{E}$ compared to placebo in adult asthmatics [61], and by a combination of vitamins $\mathrm{C}, \mathrm{E}$ and $\beta$-carotene in non-asthmatics [62]. These two studies $[61,62]$ did not include single nutrient groups, for comparative purposes, and so it not clear whether the effect is due to the combination of nutrients. However, Biltagi et al. [63] have shown that a combination of omega- 3 fatty acids, vitamin $\mathrm{C}$ and zinc supplementation given for 6 weeks to 60 children with moderate persistent asthma, was more effective than either intervention alone in improving lung function and reducing sputum LTC4-E4 levels and inflammatory cell counts. To our knowledge the present study is the first to compare the single use of either omega- 3 fatty acids or vitamin $\mathrm{C}$ to the combination of these supplements. Although both omega-3 fatty acids and vitamin $\mathrm{C}$ alone significantly attenuated airway inflammation, the combined treatment of these two nutrients did not provide a greater anti-inflammatory effect or suppression of bronchoconstriction that either treatment alone. This observation runs contrary to our hypotheses that the combination of these two nutrients, compared to each nutrient in isolation, would confer greater protection against airway inflammation and HIB in asthma. Without the measurement of relevant oxidative stress and inflammatory markers in exhaled breath it is difficult to pinpoint the reason as to why we saw no additional benefit with the combination treatment. However, a possible explanation for this observation may relate to the fact that while fish oil results in a decreased capacity of inflammatory cells to synthesize COX-2 and 5-LO-derived pro-inflammatory eicosanoids $[64,65]$ via inhibition of the transcription factor NF- $\kappa$ B, vitamin $C$ has also been shown to modulate the activation of NF- $\kappa \mathrm{B}$, and the subsequent release of pro-inflammatory mediators [49]. Therefore, it is plausible that either the dose of fish oil or vitamin C was optimal, such that when these nutrients were combined no additional effects on airway inflammation and pulmonary function were possible. It should be noted that since we have previously shown that $3.2 \mathrm{~g} /$ day EPA, $\sim 2.0$ $\mathrm{g} /$ day DHA and $1500 \mathrm{mg} /$ day ascorbic acid are effective in reducing airway inflammation and the severity of EIB/HIB in elite athletes and asthmatic patients $[7,8,10,18]$, it was decided to use these supplement dosages in the present study.

In conclusion, we have demonstrated that both fish oil and vitamin $\mathrm{C}$ supplementation are both effective in ameliorating airway inflammation and HIB in asthmatic individuals, while treatment with fish oil and vitamin $\mathrm{C}$ in combination does not provide a greater antiinflammatory effect or suppression in bronchoconstriction than either intervention alone. It is important to recognize that the subjects in the present study were asthmatics with documented HIB, and therefore the conclusions drawn from this small proof-of-concept study should not be generalized to all individuals with asthma.

\section{Author Contribution}

All authors fulfilled conditions of authorship: (1) substantial contributions to conception and design of the study, acquisition of data, or analysis and interpretation of data; (2) drafting the manuscript or revising it critically for important intellectual content; and (3) final approval for the version to be published.

\section{Acknowledgements}

We would like to thanks Nordic Naturals (Watsonville, CA) for providing the active fish oil and placebo soybean oil capsules, and to thank all the subjects who participated in this study.

\section{References}

1. Akinbami LJ, Moorman JE, Liu X (2011) Asthma prevalence, health care use, and mortality: United States, 2005-2009. Natl Health Stat Report : 1-14.

2. Sinha T, David AK (2003) Recognition and management of exercise-induced bronchospasm. Am Fam Physician 67: 769-774, 675

3. Leff JA, Busse WW, Pearlman D, Bronsky EA, Kemp J, et al. (1998) Montelukast, a leukotriene-receptor antagonist, for the treatment of mild asthma and exercise-induced bronchoconstriction. N Engl J Med 339: 147-152.

4. Drazen JM, Silverman EK, Lee TH (2000) Heterogeneity of therapeutic responses in asthma. Br Med Bull 56: 1054-1070.

5. Horrocks LA, Yeo YK (1999) Health benefits of docosahexaenoic acid (DHA) Pharmacol Res, 40: 211-225

6. Misso NL, Brooks-Wildhaber J, Ray S, Vally H, Thompson PJ (2005) Plasma concentrations of dietary and nondietary antioxidants are low in severe asthma. The European respiratory journal: official journal of the European Society for Clinical Respiratory Physiology 26: 257-264

7. Mickleborough TD, Lindley MR, Ionescu AA, Fly AD (2006) Protective effect of fish oil supplementation on exercise-induced bronchoconstriction in asthma. Chest 129: 39-49.

8. Mickleborough TD, Murray RL, Ionescu AA, Lindley MR (2003) Fish oil supplementation reduces severity of exercise-induced bronchoconstriction in elite athletes. Am J Respir Crit Care Med 168: 1181-1189.

9. Mickleborough TD, Vaughn CL, Shei R-J, Davis EM, Wilhite DP (2013) Marine lipid fraction PCSO- (lyprinol/omega $\mathrm{XL}$ ) of the New Zealand green 
Citation: Mickleborough TD, Lindley MR (2014) The Effect of Combining Fish Oil and Vitamin C on Airway Inflammation and Hyperpnea-Induced Bronchoconstriction in Asthma. J Allergy Ther 5: 184. doi:10.4172/2155-6121.1000184

Page 9 of 10

lipped mussel attenuates hyperpnea-induced bronchoconstriction in asthma. Respiratory medicine 197: 1152-1163

10. Tecklenburg-Lund S, Mickleborough TD, Turner LA, Fly AD, Stager $\mathrm{JM}$, et al. (2010) Randomized controlled trial of fish oil and montelukast and their combination on airway inflammation and hyperpnea-induced bronchoconstriction. PLoS One 5: e13487

11. von Schacky C, Kiefl R, Jendraschak E, Kaminski WE (1993) n-3 fatty acids and cysteinyl-leukotriene formation in humans in vitro, ex vivo, and in vivo. $J$ Lab Clin Med 121: 302-309.

12. Mickleborough TD, Head SK, Lindley MR (2011) Exercise-induced asthma: nutritional management. Curr Sports Med Rep 10: 197-202.

13. Serhan CN, Chiang N, Van Dyke TE (2008) Resolving inflammation: dual antiinflammatory and pro-resolution lipid mediators. Nat Rev Immunol 8: 349-361.

14. Serhan CN, Yang R, Martinod K, Kasuga K, Pillai PS, et al. (2009) Maresins: novel macrophage mediators with potent antiinflammatory and proresolving actions. J Exp Med 206: 15-23.

15. Fujisawa T (2005) Role of oxygen radicals on bronchial asthma. Curr Drug Targets Inflamm Allergy 4: 505-509.

16. Milan SJ, Hart A, Wilkinson M (2013) Vitamin C for asthma and exerciseinduced bronchoconstriction. Cochrane database of systematic reviews, 10: CD010391

17. Hemilä $\mathrm{H}$ (2013) Vitamin $\mathrm{C}$ may alleviate exercise-induced bronchoconstriction: a meta-analysis. BMJ Open 3.

18. Tecklenburg SL, Mickleborough TD, Fly AD, Bai Y, Stager JM (2007) Ascorbic acid supplementation attenuates exercise-induced bronchoconstriction in patients with asthma. Respir Med 101: 1770-1778.

19. Anderson SD, Argyros GJ, Magnussen H, Holzer K (2001) Provocation by eucapnic voluntary hyperpnoea to identify exercise induced bronchoconstriction. Br J Sports Med 35: 344-347.

20. Parsons JP, Hallstrand TS, Mastronarde JG, Kaminsky DA, Rundell KW et al. (2013) An official American Thoracic Society clinical practice guideline: exercise-induced bronchoconstriction. American journal of respiratory and critical care medicine 187: 1016-1027

21. [No authors listed] (1995) Standardization of Spirometry, 1994 Update. American Thoracic Society. Am J Respir Crit Care Med 152: 1107-1136.

22. Miller MR, Hankinson J, Brusasco V, Burgos F, Casaburi R, et al. (2005) Standardisation of spirometry. Eur Respir J 26: 319-338.

23. [No authors listed] (1999) Recommendations for standardized procedures for the on-line and off-line measurement of exhaled lower respiratory nitric oxide and nasal nitric oxide in adults and children-1999. This official statement of the American Thoracic Society was adopted by the ATS Board of Directors, July 1999. Am J Respir Crit Care Med 160: 2104-2117.

24. Horvath I, Hunt J, Barnes PJ, Alving K, Antczak A et al. (2005) Exhaled breath condensate: methodological recommendations and unresolved questions. The European respiratory journal: official journal of the European Society for Clinical Respiratory Physiology 26: 523-548

25. Koczulla R, Dragonieri S, Schot R, Bals R, Gauw SA, et al. (2009) Comparison of exhaled breath condensate $\mathrm{pH}$ using two commercially available devices in healthy controls, asthma and COPD patients. Respir Res 10: 78.

26. Santanello NC, Barber BL, Reiss TF, Friedman BS, Juniper EF et al. (1997) Measurement characteristics of two asthma symptom diary scales for use in clinical trials. The European respiratory journal: official journal of the European Society for Clinical Respiratory Physiology 10: 646- 651

27. Schakel SF, Jasthi B, Van Heel N, Harnack L (2009) Adjusting a nutrien database to improve calculation of percent calories from macronutrients. $J$ Food Comp Anal 22: 32-36

28. Wolyniak CJ, Brenna JT, Murphy KJ, Sinclair AJ (2005) Gas chromatographychemical ionization-mass spectrometric fatty acid analysis of a commercial supercritical carbon dioxide lipid extract from New Zealand green-lipped mussel (Perna canaliculus). Lipids 40: 355-360.

29. Hunt JF, Fang K, Malik R, Snyder A, Malhotra N, et al. (2000) Endogenous airway acidification. Implications for asthma pathophysiology. Am J Respir Crit Care Med 161: 694-699.

30. Accordino R, Visentin A, Bordin A, Ferrazzoni S, Marian E, et al. (2008) Long- term repeatability of exhaled breath condensate $\mathrm{pH}$ in asthma. Respir Med 102: $377-381$

31. Montuschi P, Barnes PJ (2002) Exhaled leukotrienes and prostaglandins in asthma. J Allergy Clin Immunol 109: 615-620.

32. ElHalawani SM, Ly NT, Mahon RT, Amundson DE (2003) Exhaled nitric oxide as a predictor of exercise-induced bronchoconstriction. Chest 124: 639-643.

33. Schubert R, Kitz R, Beermann C, Rose MA, Lieb A, et al. (2009) Effect of n-3 polyunsaturated fatty acids in asthma after low-dose allergen challenge. Int Arch Allergy Immunol 148: 321-329.

34. Grimminger F, Mayer K, Kiss L, Walmrath D, Seeger W (2000) PAF-induced synthesis of tetraenoic and pentaenoic leukotrienes in the isolated rabbit lung Am J Physiol Lung Cell Mol Physiol 278: L268-275.

35. Calder PC (2007) Immunomodulation by omega-3 fatty acids. Prostaglandins Leukot Essent Fatty Acids 77: 327-335.

36. Martin RE (1998) Docosahexaenoic acid decreases phospholipase A2 activity in the neurites/nerve growth cones of PC12 cells. J Neurosci Res 54: 805-813.

37. Lee JY, Zhao L, Youn HS, Weatherill AR, Tapping R, et al. (2004) Saturated fatty acid activates but polyunsaturated fatty acid inhibits Toll-like receptor 2 dimerized with Toll-like receptor 6 or 1. J Biol Chem 279: 16971-16979.

38. Aoki H, Hisada T, Ishizuka T, Utsugi M, Ono A, et al. (2010) Protective effect of resolvin $\mathrm{E} 1$ on the development of asthmatic airway inflammation. Biochem Biophys Res Commun 400: 128-133.

39. Haworth O, Cernadas M, Yang R, Serhan CN, Levy BD (2008) Resolvin E1 regulates interleukin 23 , interferon-gamma and lipoxin A4 to promote the resolution of allergic airway inflammation. Nature immunology 9: 873-879

40. Levy BD, Kohli P, Gotlinger K, Haworth O, Hong S et al. (2007) Protectin D1 is generated in asthma and dampens airway inflammation and hyperresponsiveness. J Immunol 178: 496-502.

41. Mickleborough TD, Tecklenburg SL, Montgomery GS, Lindley MR (2009) Eicosapentaenoic acid is more effective than docosahexaenoic acid in inhibiting proinflammatory mediator production and transcription from LPS-induced human asthmatic alveolar macrophage cells. Clinical nutrition 28: 71-77

42. Head SK, Mickleborough TD (2013) Randomized cross-over controlled pilo study of docosahexaenoic acid supplementation on airway inflammation and hyperpnea-induced bronchoconstriction in adults with asthma. Int J Asthma Allergy Immunol 9

43. Schuster GU, Bratt JM, Jiang X, Pedersen TL, Grapov D, et al. (2014) Dietary long-chain omega-3 fatty acids do not diminish eosinophilic pulmonary inflammation in mice. Am J Respir Cell Mol Biol 50: 626-636.

44. Williams NC, Hunter K, Johnson MA, Sharpe GR (2013) A randomized placebo controlled trial to compare the effects of two dosages of omega-3 PUFA on exercise-induced bronchoconstriction (abstract). British journal of sports medicine 47: e4

45. Ochs-Balcom HM, Grant BJ, Muti P, Sempos CT, Freudenheim JL, et al. (2006) Antioxidants, oxidative stress, and pulmonary function in individuals diagnosed with asthma or COPD. Eur J Clin Nutr 60: 991-999.

46. Andreadis AA, Hazen SL, Comhair SA, Erzurum SC (2003) Oxidative and nitrosative events in asthma. Free Radic Biol Med 35: 213-225.

47. Rahman I (2002) Oxidative stress and gene transcription in asthma and chronic obstructive pulmonary disease: antioxidant therapeutic targets. Curr Drug Targets Inflamm Allergy 1: 291-315.

48. Barnes PJ, Adcock IM (1997) NF-kappa B: a pivotal role in asthma and a new target for therapy. Trends Pharmacol Sci 18: 46-50.

49. Cárcamo JM, Pedraza A, Bórquez-Ojeda O, Golde DW (2002) Vitamin C suppresses TNF alpha-induced NF kappa B activation by inhibiting I kappa B alpha phosphorylation. Biochemistry 41: 12995-13002.

50. Fogarty A, Lewis SA, Scrivener SL, Antoniak M, Pacey S, et al. (2006) Corticosteroid sparing effects of vitamin $\mathrm{C}$ and magnesium in asthma: a randomised trial. Respir Med 100: 174-179.

51. Mohsenin V, Dubois AB, Douglas JS (1983) Effect of ascorbic acid on response to methacholine challenge in asthmatic subjects. Am Rev Respir Dis 127: 143 147 
Citation: Mickleborough TD, Lindley MR (2014) The Effect of Combining Fish Oil and Vitamin C on Airway Inflammation and Hyperpnea-Induced Bronchoconstriction in Asthma. J Allergy Ther 5: 184. doi:10.4172/2155-6121.1000184

Page 10 of 10

52. Zuskin E, Lewis AJ, Bouhuys A (1973) Inhibition of histamine-induced airway constriction by ascorbic acid. J Allergy Clin Immunol 51: 218-226.

53. Ting S, Mansfield LE, Yarbrough J (1983) Effects of ascorbic acid on pulmonary functions in mild asthma. J Asthma 20: 39-42.

54. Malo JL, Cartier A, Pineau L, L'Archevêque J, Ghezzo H, et al. (1986) Lack of acute effects of ascorbic acid on spirometry and airway responsiveness to histamine in subjects with asthma. J Allergy Clin Immunol 78: 1153-1158.

55. Kordansky DW, Rosenthal RR, Norman PS (1979) The effect of vitamin C on antigen-induced bronchospasm. J Allergy Clin Immunol 63: 61-64.

56. Fogarty A, Lewis SA, Scrivener SL, Antoniak M, Pacey S, et al. (2003) Oral magnesium and vitamin $C$ supplements in asthma: a parallel group randomized placebo-controlled trial. Clin Exp Allergy 33: 1355-1359.

57. Cohen HA, Neuman I, Nahum H (1997) Blocking effect of vitamin C in exerciseinduced asthma. Arch Pediatr Adolesc Med 151: 367-370.

58. Schachter EN, Schlesinger A (1982) The attenuation of exercise-induced bronchospasm by ascorbic acid. Ann Allergy 49: 146-151.

59. Rothberg KG, Hitchcock M (1983) Effects of ascorbic acid deficiency on the in vitro biosynthesis of cyclooxygenase metabolites in guinea pig lungs. Prostaglandins Leukot Med 12: 137-147.

60. Ogilvy CS, DuBois AB, Douglas JS (1981) Effects of ascorbic acid and indomethacin on the airways of healthy male subjects with and without induced bronchoconstriction. J Allergy Clin Immunol 67: 363-369.

61. Trenga CA, Koenig JQ, Williams PV (2001) Dietary antioxidants and ozoneinduced bronchial hyperresponsiveness in adults with asthma. Arch Environ Health 56: 242-249.

62. Romieu I, Meneses F, Ramirez M, Ruiz S, Perez Padilla R, et al. (1998) Antioxidant supplementation and respiratory functions among workers exposed to high levels of ozone. Am J Respir Crit Care Med 158: 226-232.

63. Biltagi MA, Baset AA, Bassiouny M, Kasrawi MA, Attia M (2009) Omega-3 fatty acids, vitamin $\mathrm{C}$ and $\mathrm{Zn}$ supplementation in asthmatic children: a randomized self-controlled study. Acta Paediatr 98: 737-742.

64. Camandola S, Leonarduzzi G, Musso T, Varesio L, Carini R, et al. (1996) Nuclear factor kB is activated by arachidonic acid but not by eicosapentaenoic acid. Biochem Biophys Res Commun 229: 643-647.

65. Novak TE, Babcock TA, Jho DH, Helton WS, Espat NJ (2003) NF-kappa B inhibition by omega -3 fatty acids modulates LPS-stimulated macrophage TNFalpha transcription. Am J Physiol Lung Cell Mol Physiol 284: L84-89. 